\title{
A Gestão de Contratos na Administração Pública
}

Ataniela Rogéria Gonçalves Gomes ${ }^{1}$

\begin{abstract}
Resumo: A Gestão de Contratos Administrativos é atualmente uma atividade muito complexa, se considerarmos que operacionalizar a aquisição de um bem é mais simples que se deparar com as etapas burocráticas que lhe antecede ou lhe sucede. Fosse exemplar a etapa preliminar e preparatória (na qual incluímos a elaboração do Termo de Referência e/ou do Projeto Básico, Editais, entre outros) certamente teríamos menos problemas no tocante à gestão e fiscalização dos contratos administrativos em geral. Neste artigo abordamos a importância da atuação de fiscalização e controle do Núcleo de Gestão de Contratos - NGC da Empresa Baiana de Águas e Saneamento S.A. - EMBASA para o aprimoramento da abordagem que faremos em torno da busca pela celebração da melhor aquisição para a melhor consecução dos fins públicos.
\end{abstract}

Palavras-chave: Gestão. Contratos Administrativos. Fiscalização. Controle. Aquisição.

\section{The Contract Management in Public Administration}

\begin{abstract}
The Management Administrative Contracts currently is a very complex activity, considering that operationalize the acquisition of an asset is simpler than you encounter bureaucratic steps that precedes him or her succeed. Was exemplary preliminary and preparatory stage (in which included the preparation of the Terms of Reference and / or Basic Project, Notices, etc.) we would certainly have fewer problems regarding the management and supervision of administrative contracts in general. This article deals with the importance of the role of supervision and control of the Contracts Management Unit - NGC Company Bahia Water and Sanitation SA - EMBASA to improve the approach that we do around the search for the celebration of the best acquisition for the best achievement of public purposes.
\end{abstract}

Keywords: Management. Administrative contracts. Oversight. Control. Acquisition.

\section{Introdução}

De acordo com Santana e Camarão (2015, p.13) considera-se Administração Pública, para efeito de formalização de um contrato administrativo, os órgãos e entidades da Administração Direta (União, Estados, Distrito Federal e Municípios) e fundos especiais, as autarquias, as fundações públicas, as empresas públicas, as sociedades de economia mista e demais entidades controladas direta ou indiretamente pelas entidades da Administração Direta anteriormente citadas.

\footnotetext{
${ }^{1}$ Graduada em Administração de Empresas - Universidade Norte do Paraná - UNOPAR; Graduada em Licenciatura em Matemática Universidade do Estado da Bahia - UNEB; Especialista em Metodologia do Ensino da Matemática e Física - Faculdade Internacional de Curitiba - FACINTER; Especialista em Metodologia do Ensino da Matemática - Faculdade São Luís de França ; Especializanda em Gestão Pública - Universidade Federal do Vale do São Francisco - UNIVASF. Contato: ataniela.tani@ hotmail.com
} 
Contratos administrativos, no entanto, na concepção de Di Pietro (2012, p. 299) são ajustes que a Administração, nessa qualidade, celebra com pessoas físicas ou jurídicas, públicas ou privadas para a consecução de fins públicos, segundo regime jurídico de direito público.

No caso específico das empresas públicas e sociedades de economia mista que explorem atividade econômica de produção ou comercialização de bens ou prestação de serviços, o art. 173, parágrafo $1^{\circ}$, da Constituição Federal previu que lei específica irá regular suas contratações e é possível perceber que até a presente data essa lei não foi editada.

No atual regime licitatório e contratual administrativo brasileiro, a maioria dos contratos administrativos está submisso às regras especiais de norma (Lei 8.666/93). Em outros casos é necessária uma aproximação das regras contratuais às práticas do direito privado, observados (diz a Constituição Federal) e tão somente os princípios da Administração Pública.

Para melhor caracterização da temática aqui apresentada surge a Empresa Baiana de Águas e Saneamento - EMBASA, caracterizada como Empresa Pública de Economia Mista, que firma contratos administrativos regulamentados pelas Leis Federais 8.666/1993 e 10.520/2002 e pela Lei Estadual 9.433/2005.

Não podemos esquecer que as empresas públicas e demais sociedades governamentais que atuam em regime concorrencial detêm finalidades empresariais e objetivos sociais específicos a cumprir, e devem firmar seus contratos visando sempre o interesse público.

Neste contexto, para a elaboração deste projeto de pesquisa surge o seguinte questionamento: De que forma a Empresa Baiana de Águas e Saneamento - EMBASA consegue alinhar os procedimentos de controle e eficiência para alcançar, no sentido finalístico da expressão, uma ótima contratação?

Considerando que existem diversos temas polêmicos que envolvem o tema contratos administrativos é necessário ratificar que de modo geral a Administração procura atingir o cumprimento total da finalidade pública e para isso trava diversas relações jurídicas com diferentes setores da sociedade.

Os procedimentos para celebração de contratos com a Administração são previamente fixados pelo respectivo ente público, afastada a participação direta do particular na elaboração do contrato. A administração não é inteiramente livre na criação de tais cláusulas, limita-se ao que impõem as leis, os regulamentos e os princípios que regem todos os contratos administrativos. Além disso, o contrato deve ser elaborado considerando os termos do edital e da proposta, a qual as partes vinculam. (SANTANA;CAMARÃO, 2015, p. 16).

Neste tocante, a Gestão de Contratos tem papel indispensável, pois cabe a esta acompanhar cada etapa e analisar o cumprimento contratual bem como atuar desde o planejamento das atividades até a conclusão das mesmas. 
Assim sendo, o objetivo geral deste trabalho é compreender a relevância da atuação do Núcleo de Gestão de Contratos no controle dos Contratos Administrativos firmados pela Empresa Baiana de Águas e Saneamento - EMBASA considerando as especificidades de cada serviço realizado. E no intuito de alcançar este objetivo geral, estabeleceremos os seguintes objetivos específicos:

- Analisar a forma como são planejados, firmados, executados, acompanhados e finalizados os contratos administrativos na empresa objeto de estudo.

- Identificar as etapas constituintes bem como a eficiência dos agentes envolvidos na efetivação dos contratos administrativos realizados na referida empresa;

- Apreender na prática as concepções básicas que englobam todo o processo de contratação na Administração pública.

\section{Procedimentos Metodológicos}

A metodologia de pesquisa qualitativa e bibliográfica serviu de suporte fundamental para a elaboração deste artigo tendo em vista que existe um rico acervo de materiais bibliográficos que abordam esta temática e que certamente serviram de referencial teórico para o aprofundamento deste.

Segundo Gil (1999, p. 65):

A pesquisa bibliográfica deve ser desenvolvida a partir de material já elaborado, construído principalmente de livros e artigos científicos. Embora em quase todos os estudos seja algum tipo de trabalho desta natureza, há pesquisas desenvolvidas exclusivamente a partir de fontes bibliográficas.

Será realizado ainda um estudo de caso baseado numa abordagem qualitativa que tem como objetivo revelar elementos importantes das atividades desenvolvidas pelo Núcleo de Gestão de Contratos da Empresa Baiana de Águas e Saneamento no sentido de garantir o melhor cumprimento dos contratos administrativos firmados com os particulares.

Para coleta das informações e objetivando melhor delimitar o foco da pesquisa será utilizada a Unidade Regional de Paulo Afonso como referência para obtenção de tais informações.

Tal pesquisa consistirá na coleta de dados através de entrevistas realizadas na referida empresa com questões direcionadas para o pessoal (equipe) que trabalha diretamente no com a atividade de interesse deste projeto. Um ponto interessante a destacar nesta pesquisa é que o foco de toda a proposta girará em torno da intenção primordial de atingir os objetivos da mesma.

A diversidade de informações a ser adquiridas através deste método possibilitará o enriquecimento da pesquisa e a melhor contextualização do tema. Para isso será imprescindível trilhar um caminho qualitativo no intuito de adentrar naturalmente o contexto analisado, estando em contato direto com quem trabalha cotidianamente nesta atividade. 


\section{Discussão Teórica}

\section{Gestão de Contratos Administrativos e a Administração Pública}

Na composição das atividades de gestão de contratos administrativos é possível enxergar claramente a necessidade de um ator fundamental que possa atuar fundamentalmente como "olhos" da Administração. Tal figura importante chama-se gestor. Ao gestor cabe a representação da Administração na execução do contrato. Ele será designado no projeto básico/termo de referência e será nomeado entre os servidores que tenham o conhecimento técnico do objeto contratado ou o titular da unidade organizacional formada para fiscalizar a obrigação contratual.

Independente de qualquer outra preocupação da Administração, o controle e a inspeção dos contratos administrativos devem ser feitos com o fim de verificar a execução do objeto contratual de forma integral.

Para isso, o gestor/fiscal deve ser diligente e agir com pró-atividade, presteza e rendimento funcional, exercendo uma ação fiscalizadora de modo sistemático e permanente, de maneira a fazer cumprir, rigorosamente os prazos, condições, qualificações e especificações previstas no instrumento contratual.

O particular, no entanto, irá responder pelos danos causados à Administração e a terceiros decorrentes do rompimento ou da não-conclusão do pactuado anteriormente no contrato administrativo.

Neste aspecto, como afirmam Santana e Camarão (2015, p. 129), “os contratos públicos são regidos por normas e princípios do direito público, recorrendo ao direito privado apenas supletivamente, jamais substituindo ou deixando de aplicar as regras privativas da Administração".

Fiscalizar a execução de um contrato administrativo, sob a ótica da Administração Pública, não é apenas uma mera atividade formal. É preciso observar atentamente qual será o tipo de prestação de serviço, as formas e prazos de entrega, bem como a qualidade e a quantidade, conforme o previsto no instrumento contratual firmado entre as partes.

Assim sendo, quando bem geridos os contratos administrativos, existe a plena certeza da garantia de resultados ótimos para a sociedade, quer seja na prestação de serviços, no fornecimento de bens ou na utilização de imóveis.

\section{Contratos de serviços terceirizados}

Mesmo sendo considerada por alguns teóricos uma preocupante realidade, devido ao surgimento de um expressivo contingente de "contratados" à margem da lei e da Constituição, ao lado 
dos titulares de cargos ou empregos públicos, dos ocupantes de funções comissionadas e dos contratados para atender a necessidades realmente temporárias de excepcional interesse público, a terceirização atua como um modelo de gestão no qual a Administração Pública contrata os serviços de terceiros (particulares), porém esta não pode ser confundida com a terceirização de mão de obra.

Terceirização é a contratação de serviços por meio de empresa, intermediária entre o tomador de serviços e a mão de obra, mediante contrato de prestação de serviços. A relação de emprego se faz entre o trabalhador e a empresa prestadora de serviços, e não diretamente com o contratante destes. (SANTANA; CAMARÃO, 2015, p. 152).

Nos dias atuais, ao iniciar os procedimentos de contratação de serviços de terceiros, a Administração se preocupa em organizar as fases licitatórias. É preciso reforçar que é importante também que exista uma preocupação equivalente em relação ao bom gerenciamento destes contratos, pois a própria Administração pode vir a ser responsabilizada solidariamente e/ou subsidiariamente referente aos encargos previdenciários e trabalhistas pertinentes e ainda porque a eficácia no gerenciamento permitirá uma avaliação da execução do serviço prestado e, principalmente, o acompanhamento e a verificação de que está atingindo o seu objetivo principal.

É importante reforçar que tão importante quanto a responsabilização do administrador público é que ele tenha consciência de que ele gerencia o dinheiro público e que por isso deve agir com honestidade e principalmente obedecendo aos princípios da legalidade.

No dia a dia, difícil é o entendimento de que a Administração contrata os serviços, e não a mão de obra, devendo acompanhar esse contrato, observando se a empresa vem cumprindo todas as exigências habilitatórias dispostas no edital, como, por exemplo, o recolhimento dos encargos trabalhistas e previdenciários dos empregados que lhe estão prestando serviço. (VIEIRA; VIEIRA; FURTADO; FURTADO; MUKAI; SANTANNA, 2015, p.46)

É permitida a terceirização nos casos de atividades de segurança e vigilância; atividade de conservação e limpeza; serviços especializados ligados à atividade-meio do tomador de serviços. Deve-se fazer uma exceção ao trabalho temporário, no qual também se permite a contratação de trabalhadores para atuarem na atividade-fim da empresa.

Num primeiro momento, pode-se definir como atividade-meio aquela que não é representativa do objeto da empresa, desfragmentada, portanto, de seu processo produtivo, configurando-se como serviço necessário (paralelo ou secundário), porém não essencial.

A atividade-fim é aquela que compreende as atividades essenciais e normais para as quais a empresa se constitui. É o seu objetivo a exploração do seu ramo de atividade devidamente expresso em contrato social. 
Assim sendo, a terceirização deve sempre ser vista como exceção, só sendo possível nos casos específicos anteriormente mencionados, e, em todo caso, ainda que nestas condições, a terceirização somente será considerada lícita se obedecer a todos os requisitos exigidos pela lei.

Importante ponto a destacar, e que é comum à terceirização, seja nas atividades de conservação e limpeza, segurança e vigilância, e de serviços especializados relacionados com as atividades-meio, é:

\begin{abstract}
A proibição expressa de existência de pessoalidade e subordinação com o tomador de serviços, sendo que, contatada a presença de tais requisitos, a relação de emprego também passa a existir com este tomador. Tal fato não ocorre, contudo, quando o tomador for integrante da Administração Pública, diante da necessidade de aprovação prévia em concurso público, como determina a Constituição Federal. Da mesma forma, situação especial ocorre no trabalho temporário, no qual a subordinação se manifesta entre trabalhador e as empresas, fornecedores e cliente. (SANTANA; CAMARÃO, 2015, p. 152).
\end{abstract}

Para melhor esclarecimento, com exceção da terceirização do trabalho temporário, nos demais três casos de terceirização, não existe limite de tempo determinado pela lei para que o trabalhador que esteja empregado na empresa prestadora do serviço (fornecedora da mão de obra) continue prestando seus serviços para o mesmo tomador, desde que não exista a pessoalidade e a subordinação para com ele conforme exposto acima.

Dessa forma, no caso de uma terceirização que esteja de acordo com a lei, o prestador de serviços será empregado da empresa terceirizada, mantendo com o tomador apenas uma relação de trabalho.

Os vínculos trabalhistas, a assinatura da Carteira de Trabalho e Previdência Social - CTPS, o pagamento dos salários e das demais verbas a que tiver direito, bem como a aplicação de penalidades trabalhistas e/ou punições, são sempre de competência da prestadora.

\title{
Estudo de Caso
}

Para construir este trabalho percebe-se a necessidade de realização de um estudo de caso que possibilite a obtenção de informações/contribuições de pessoas envolvidas diretamente com a atividade de Gestão de Contratos Administrativos da Empresa Baiana de Águas e Saneamento S.A.

A Empresa Baiana de Águas e Saneamento S.A. - EMBASA foi criada pela Lei Estadual número 2.929, em 11 de maio de 1971 e atualmente atua como empresa de grande porte da atividade de saneamento básico do país, administrando o abastecimento de água e esgotamento sanitário de boa parte do estado da Bahia. 
Após a definição do planejamento estratégico da empresa, a EMBASA apresenta suas atividades divididas em processos e a hierarquia é exercida de acordo com subdivisões de assessoramento.

No tocante à presidência (órgão de maior hierarquia da empresa) no exercício das atividades referentes a licitações e contratos existe uma divisão denominada PLC (Unidade de Licitações e Contratos) e ainda algumas subdivisões da mesma, que prestam suporte aos órgãos decisórios centralizados (localizados na cidade de Salvador - BA) da empresa e ainda aos órgãos descentrados (Unidades Regionais - localizadas em cidades-pólo do interior do estado da Bahia).

Cada Unidade Regional, por sua vez, possui em sua sede um setor denominado Núcleo de Gestão de Contratos - NGC que atua diretamente na execução de contratos administrativos e controle/apoio dos contratos de terceirização sob responsabilidade da respectiva Unidade Regional.

Como objeto central desta pesquisa, o estudo de caso ora exposto foi realizado somente na Unidade Regional de Paulo Afonso que abrange municípios da região, a exemplo dos municípios de Paulo Afonso, Glória, Santa Brígida, Jeremoabo, Coronel João Sá, Pedro Alexandre, Abaré, Chorrochó, Canudos e os respectivos povoados. Com base nesta, serão investigados diversos aspectos ligados aos produtos oferecidos pelo Núcleo de Gestão de Contratos - NGC, analisando e discutindo a importância das atividades desenvolvidas no mesmo para o melhor desenvolvimento dos contratos administrativos firmados na referida Empresa.

\section{Discussão dos Resultados}

\section{Núcleo de Gestão de Contratos - NGC/EMBASA}

O NGC/EMBASA da Unidade Regional de Paulo Afonso - UNP é composto pelo gestor/fiscal do contrato e 02 funcionários de apoio (Assistentes Administrativos) atuando na parte burocrática da gestão, prestando assessoria/suporte às tomadas de decisão pertinentes as atividades que desenvolvem.

Cabe destacar que a gestão documental dos Contratos Administrativos da Instituição Investigada (EMBASA) fica sob responsabilidade do Núcleo de Gestão de Contratos, ao qual compete o acompanhamento de todos os processos que envolvem as diversas etapas que vão desde o apoio às áreas requisitantes quanto a elaboração dos editais e dos instrumentos contratuais propriamente ditos.

O controle adequado dos documentos, desde sua elaboração, torna-se necessário para que todos sejam padronizados em termos de procedimentos técnicos antes, durante e após a execução contratual. 
Nesta ótica, o papel do gestor é fundamental, pois ele vai determinar as diretrizes a serem analisadas pela equipe do NGC, pois ninguém melhor do que ele para indicar quais as cautelas que devem ser tomadas na concepção dos Termos de Referência e/ou Projeto Básico (que servirão de espelho para o edital e a minuta do contrato), tendo em vista que o mesmo possui maior experiência e conhecimento técnico da área para identificar/apontar as principais mazelas que ocorrem durante a execução do ajuste.

Ao NGC enquanto apoio cumpre dentre outras atividades, observar as seguintes documentações:

\begin{tabular}{|c|c|}
\hline \multirow{4}{*}{$\begin{array}{l}\text { Documentações que devem ser } \\
\text { exigidas desde o início do contrato }\end{array}$} & \multirow{2}{*}{$\begin{array}{l}\text { Comprovante do recolhimento do valor referente à Garantia Contra } \\
\text { Certidões Negativas de Débito com a Administração Pública }\end{array}$} \\
\hline & \\
\hline & Atestado de Capacidade Técnica \\
\hline & Regularidade Fiscal do Contratado \\
\hline & Notas fiscais - Medições e Resumos da Nota fiscal \\
\hline & Carta de Justificativa da tabela FAP na GFIP \\
\hline $\begin{array}{l}\text { Documentações exigidas } \\
\text { mensalmente do Contratado } \\
\text { uando do encaminhamento de } \\
\text { medições parciais }\end{array}$ & $\begin{array}{l}\text { GFIP completa: } \\
\text { - Protocolo de envio de arquivos - Conectividade Social; } \\
\text { - RE - Relação de Trabalhadores (Referente ao Tomador - } \\
\text { EMBASA; } \\
\text { - Resumo das informações à Previdência Social constantes no } \\
\text { arquivo SEFIP - Tomador de Serviços/Obras; } \\
\text { - Relatório Analítico da GRF bem como comprovante de } \\
\text { pagamento; } \\
\text { - Relatório Analítico da GPS bem como comprovante de } \\
\text { - } \text { Cópamento; } \\
\text { - Tomador Folha de Pagamento com as informaçães pertinentes ao } \\
\text { - Comprovante de declaração das contribuições a recolher à } \\
\text { - Previdência Social; } \\
\text { - Fedidão conjunta Negativa de débitos relativos aos Tributa da União; } \\
\text { - Certificado de Regularidade do FGTS-CRF; } \\
\text { - Certidão Negativa de Débitos Tributários - Estadual; } \\
\text { - CNDT - Certidão Negativa de Débitos Trabalhistas. } \\
\text { - Outros que sejam pertinentes ao objeto contratual. }\end{array}$ \\
\hline & \\
\hline
\end{tabular}

\section{Fiscalização de Contratos Administrativos}

No tocante à administração dos Contratos Administrativos da EMBASA, o gestor de contrato é o próprio fiscal do contrato. No entanto, alguns teóricos como Jessé Torres Pereira Júnior e Marinês Restelatto Dotti afirmam a importância de que a figura do gestor de contratos não deve ser confundida com a do fiscal de contratos já que: 


\begin{abstract}
A fiscalização é a atividade de controle e inspeção sistemática do objeto contratado pela Administração, com a finalidade de examinar ou verificar se sua execução obedece às especificações, ao projeto, aos prazos estabelecidos e demais obrigações previstas no contrato. Em resumo, é o acompanhamento cotidiano do contrato em seu local de execução, com o fim de certificar-se a Administração de que se executa o que se contratou, nem mais, nem menos. Tal é o papel que se espera do fiscal. O gestor de Contrato é a autoridade superior a que o fiscal remeterá as decisões e providências que ultrapassam a sua competência. Cabe-lhe gerenciar o contrato e decidir sobre eventuais e possíveis alterações das condições avençadas. Ao gestor, e apenas a ele, caberá a responsabilidade pela tomada de decisões gerenciais relativas à execução do contrato e à celebração de seus aditamentos. A designação do fiscal, inclusive, poderá ficar a cargo do gestor de contrato. (PEREIRA JÚNIOR; DOTTI, 2011)
\end{abstract}

Porém, embora tal informação seja relevante, cumpre destacar que o Tribunal de Contas da União - TCU, no Acórdão n 2.917/2010 - Plenário, Rel. Min. Valmir Campelo, deixou assentado que 'o servidor designado para exercer o cargo de fiscal não pode oferecer recusa, porquanto não de trata de ordem ilegal. Entretanto, tem a opção de expor ao superior hierárquico as deficiências e limitações que possam impedi-lo de cumprir diligentemente suas obrigações. A opção que não se aceita é uma atuação a esmo (com imprudência, negligência, omissão, ausência de cautela e de zelo profissional), sob pena de configurar grave infração à norma legal'.

Ao questionar aos colaboradores do NGC/EMBASA da UNP quais as principais competências a serem identificadas no gestor/fiscal de contratos, as respostas foram:

- Possuir boa reputação ética e profissional;

- Possuir conhecimentos específicos suficientes a respeito do objeto a ser fiscalizado;

- Não estar respondendo a processo de sindicância ou processo administrativo disciplinar na empresa;

- Não possuir em seus registros funcionais punições em decorrência de atos lesivos ao patrimônio público, em qualquer esfera de governo;

- Não possuir vínculo externo de nenhuma espécie com a empresa contratada;

- Não haver sido condenado em processo criminal por crimes contra a Administração Pública (Código Penal, Lei nº 7.494/1996 e Lei nº 8.429/1992);

- Possuir aptidão para negociar, flexibilidade e firmeza para garantir o cumprimento do objeto contratado.

\title{
Considerações Finais
}

Todos nós sabemos que, abastecer a Administração Pública de bens, serviços, obras, materiais e produtos, é uma atribuição seriada, formal, complexa e principalmente, instrumental. 
Cotidianamente, muitas são as atribuições do gestor/fiscal dos bens públicos: Negociações, atividades burocráticas, demandas processuais, contatos telefônicos, escritos e verbais. No entanto, deixamos muito a desejar no que diz respeito à gestão e fiscalização dos contratos, bem como na identificação das demandas e do estabelecimento de políticas e estratégias para os suprimentos necessários à consecução dos fins estatais.

É através destas atividades que o Poder Público consegue prestar seus serviços e fornecer utilidades aos mais variados setores da sociedade.

Assim sendo, esta temática torna-se indispensável ao enfatizar a importância do planejamento e da competência técnica, considerando que a operacionalização atuante dos Núcleos de Gestão de Contratos - NGC's torna a Gestão dos Contratos Administrativos da Empresa Baiana de Águas e Saneamento S.A. - EMBASA mais eficiente na medida em que o próprio ente governamental possui maior fiscalização/controle dos meios necessários à sua capacidade de atuação.

\section{Referências}

BRASIL. Tribunal de Contas da União. Licitações e contratos: orientações básicas do Tribunal de Contas da União. 3.ed. Brasília: Senado Federal, Secretaria Especial de Editoração e Publicações, 2006.

Decreto-Lei n. ${ }^{\circ}$ 200, de 25 de fevereiro de 1967: Dispõe sobre a organização da Administração Federal, estabelece diretrizes para a Reforma Administrativa e dá outras providências. Disponível em: <http://www.planalto.gov.br/ccivil/decreto-lei/Del0200.htm>. Acesso em 22 jun. 2014.

CARLI, Kalinca de. Acréscimo superior ao limite de $25 \%$ em contratos administrativos decorrentes da inexigibilidade de licitação. Informativo de Licitações e Contratos - ILC, Curitiba, n. 240, p. 124126, fev. 2014.

CHIAVENATO, Idalberto. Administração Geral e Pública. Rio de Janeiro: Elsevier, 2008. DI PIETRO, Maria Sylvia Zanella. Direito Administrativo. São Paulo: Atlas, 2012.

GIL, A. C. Métodos e Técnicas de Pesquisa Social. São Paulo: Atlas, 1999.

GONÇALVES, C. A.; MEIRELLES, A. M. O que é estratégia: histórico, conceito e analogias. In: GONÇALVES, C. A.; et al. (Org.). Administração estratégica: múltiplos enfoques para o sucesso empresarial. Belo Horizonte: UFMG/CEPEAD, 2001. p. 21-33.

Mapas Estratégicos: Convertendo Ativos Intangíveis em resultados tangíveis (Strategy Maps). Tradução: Afonso Celso de Cunha Serra. Rio de Janeiro: Elsevier, 2004.

OLIVEIRA, C. F. A gestão dos serviços de saneamento básico no Brasil. (publicado na Revista Electrónica de Geografía Y Ciencias Sociales vol. IX, n. 194, Barcelona, 2005). Disponível em: 
<http://www.google.com.br/search?hl=pt-

BR\&q=hist\%C3\%B3rico+saneamento+no+brasil\&meta=\&aq=o\&oq>. Acesso em 26 mar. 2009.

PEREIRA JÚNIOR, Jessé Torres; DOTTI, Marinês Restelatto. A responsabilidade dos fiscais da execução do contrato administrativo. Fórum de Contratação e Gestão Pública - FCGP, Belo Horizonte, ano 10, n. 120, dez. 2011.

PRESTES, M. L. M. A pesquisa e a construção do conhecimento científico. São Paulo: Respel, 2002.

SANTANA, Jair Eduardo. Termo de referência. 4.ed. Belo Horizonte: Fórum, 2014.

SANTANA, Jair Eduardo; CAMARÃO, Tatiana. Gestão e fiscalização de contratos administrativos. Belo Horizonte: Fórum, 2015.

SANTANA, Jair Eduardo; GUIMARÃES, Edgar. Licitações e o estatuto da pequena e microempresa: reflexos práticos da $\mathbf{L} C \mathbf{n}^{\circ}$ 123/06. 3.ed. rev. atual. e ampl. Belo Horizonte: Fórum, 2014.

TANAKA, Sônia Yuriko Kanashiro; PINHEIRO, Aparecida dos Santos. Vigência dos contratos de fornecimento contínuo. Informativo de Licitações e Contratos - ILC, Curitiba, n. 240, p. 127-136, fev. 2014.

VERGARA, S. C. Projetos e Relatórios de Pesquisa em Administração. São Paulo: Atlas, 2000.

VIEIRA, Antonieta Pereira; VIEIRA, Henrique Pereira; FURTADO, Madeline Rocha; FURTADO, Monique Rafaella Rocha; MUKAI, Toshio; SANTANNA, Rogério. Gestão de Contratos de Terceirização na Administração Pública: teoria e prática. Belo Horizonte: Fórum, 2015.

Como citar este artigo (Formato ABNT):

GOMES, Ataniela R. G. A Gestão de Contratos na Administração Pública. Id on Line Revista de Psicologia, Fevereiro de 2016, vol.10, n.29, p. 100-110. ISSN 1981-1179.

Recebido: 08/01/2016

Aceito:19/01/2016 